\title{
Morphologic Response
}

National Cancer Institute

\section{Source}

National Cancer Institute. Morphologic Response. NCI Thesaurus. Code C123625.

An evaluation of the morphologic response of the disease to the therapy. 